\title{
Sexual Assault Profile in Jimma University Medical Center, Southwest Ethiopia
}

This article was published in the following Dove Press journal:

Adolescent Health, Medicine and Therapeutics

\author{
Yibeltal Siraneh (D' \\ Abonesh Taye $\mathbb{D}^{2}$ \\ Fanta Asefa $^{3}$ \\ Abraraw Tesfaye ${ }^{4}$ \\ Yesuf Ahmed (iD ${ }^{5}$ \\ 'Department of Health Policy and \\ Management, Faculty of Public Health, \\ Jimma University, Jimma, Ethiopia; \\ ${ }^{2}$ Department of Nutrition and Dietetics, \\ Faculty of Public Health, Jimma \\ University, Jimma, Ethiopia; ${ }^{3}$ Department \\ of Obstetrics and Gynecology, Faculty of \\ Medical Sciences, Jimma University, \\ Jimma, Ethiopia; ${ }^{4}$ School of Information \\ Technology and Engineering, Addis Ababa \\ Institute of Technology, Addis Ababa \\ University, Addis Ababa, Ethiopia; \\ ${ }^{5}$ Department of Obstetrics and \\ Gynecology, Faculty of Medical Sciences, \\ Wello University, Dessie, Ethiopia
}

Background: Sexual assault cases are increasingly reported in Ethiopia and worldwide. However, in Ethiopia, sexual assaults' profile was not investigated well, regardless of its social, physical, and psychological impacts on survivors. Hence, this study assessed the survivors' characteristics, circumstances of the victims, and treatment offered with the view of describing the management process, and service responsiveness.

Methods: A descriptive study with 3 years retrospective chart review was conducted in Jimma University Medical Center (JUMC). Samples of 187 charts/medical records were selected using a systematic random sampling technique from the medical unit. The selected survivors' records were reviewed using a structured checklist. Data were analyzed using SPSS Version 21.0.

Results: Out of the 187 cases of sexual assaults during the study period, $67.4 \%$ were rape cases. Among these, 58.8\% were below 14 years, and $85.6 \%$ knew their assailants. Above $30 \%$ of the victims were assaulted during the daytime, and $51.9 \%$ developed perennial laceration. Threat and physical force were mostly used to coerce victims during the violence. All of the survivors were not investigated for vaginal/anal swab (for sperm analysis), and $96.8 \%$ of the victims were not tested for HIV screening. Only $8 \%$ of the victims received emergency contraception.

Conclusion and Recommendation: Children and adolescents remain the most sexually assaulted group of the population, requiring protection and appropriate medical services to ensure their well-being and reduce their suffering. Appropriate and timely intervention is needed to care for such survivors. The findings have highlighted the need for closer monitoring and better follow-up of the care and support provided in the Medical Center to sexual assault victims.

Keywords: sexual assaults, survivors, profile, retrospective, Jimma University Medical Center

\section{Introduction}

Sexual assault refers to a comprehensive range of forced sexual acts including forced touching or kissing, verbal sexual abuse, coerced intercourse, or actual vaginal, oral, and/or anal penetration, which affects millions worldwide. ${ }^{1}$ Rape is a very serious form of violence; it is sexual assault involving some type of penetration, no matter how slight, of the vagina or the anus with a person's body part or object or oral penetration by a sex organ of another person without the consent of the victim by force or threat of force, lack of consent, or inability of the victim to provide consent due to age, intoxication, or mental status. ${ }^{2}$ Rape and sexual violence are attacks on the body and dignity of a woman; such assaults have
Correspondence: Yibeltal Siraneh Tel +251917017092

Email yibeltal_siraneh@yahoo.com

Adolescent Health, Medicine and Therapeutics 2021:12 17-25 
profound psychological, medical, economic, and social consequences for the rest of life that plague survivors and their families. Victims of sexual violence face multiple social and psychological challenges. ${ }^{1,2}$

Experiencing sexual violence in childhood impacts lifelong health and well-being. According to a United Nation Publication, the toll of violence against children reaches at least 1 billion; half of the world's children every year experience violence ${ }^{3}$ and globally more than one third of women have experienced rape, physical violence, and or stalking by an intimate partner at some point in their life time. ${ }^{4}$ It is also estimated that one billion children aged 2-17 years globally have experienced physical, sexual, or emotional violence. ${ }^{5}$

In dealing with prevention and ending child maltreatment, the key concept is being familiar with the driving factors. ${ }^{6,7}$ Out of many children who get traumatized by sexual violence, few get access to the services they need at health institutions. Indeed, recognizing the condition and investing in prevention and management of cases is a question of good governance and respect for human rights. It also makes economic sense, with studies confirming violence as a major drain on national economies and making it an opportune time to raise awareness and strengthen the response of the health system. ${ }^{8}$

Global epidemiology of sexual assault is likely to differ substantially with regard to geographic location; yet violence knows no boundaries and it is not peculiar to any particular race or economic class. They include those school children who are expected to be safe in schools, as well as those found in justice and care institutions. Surprisingly, for those who are living at home with intimate partners, sexual assault is dominant. ${ }^{9}$

Violence studies from 86 countries across WHO regions of Africa, Europe, and the eastern Mediterranean show that $68 \%$ of women have experienced physical and sexual violence in their life time from an intimate partner. ${ }^{10}$ The prevalence of rape among South African girls accounts for 2,070 per 100,000 per year according to community-based reports. ${ }^{11}$ A study conducted in Ibadan State of Nigeria indicates that $15 \%$ of young females (adolescents) reported forced penetrative sexual experience, ${ }^{12}$ while a $13.8 \%$ prevalence rate was found among female students in Maiduguri. ${ }^{13}$

In Ethiopia, the reported incidence of sexual assault (8.8\%) varies from Debark $(11.5 \%)$ and Jimma Town (78.8\%). ${ }^{14,15}$ Indeed, the existence of laws alone does not reduce violence, but effective implementation, treatment, and follow-up constitute the best strategy. ${ }^{16}$ The negative impact of violence is multifaceted in terms of health and psychosocial issues. Hence, implementing secondary prevention mechanisms, providing health services as per the standard, approaches, and competency of health professionals in providing care are necessary conditions to avert the negative impact of violence. Jimma University Medical Center (JUMC) had a standard tool to assess and treat every victim coming to the clinic free of charge through trained nurse professionals in consultation with gynecology specialists. At each encounter, counseling or psychotherapy services are expected to be given by nurse professionals and then at each follow-up visit too. The role of the health professionals and availability of other critical resources/ equipment take the lions share to reduce the negative impact of violence. However, sexual assaults profile such as the victim's characteristics, circumstances of the assault, laboratory findings, and treatment/services offered were not clearly known in the study area. Therefore, the main objective of this study was to describe sexual assaults' profile recorded during managing the case at JUMC, assess the availability of care and support, and forward pertinent recommendations for improvement in these crucial services.

\section{Methods}

\section{Study Setting and Period}

The study was conducted in Jimma University Medical Center (JUMC). The center is found in Jimma Town, Oromia Regional State, Southwestern Ethiopia. Data collection was carried out from February 15, 2018 to April 15, 2018. JUMC has a catchment population of about 15 million people. The center has an annual out-patient case load of 160,000 and 45,000 in-patients. It provides services to a diverse population from three regional states, namely Oromia, Southern Nations Nationalities and Peoples, as well as Gambella. The center has an independent sexual assault clinic that started the work independently on August 19, 2014. The clinic has standard tools to assess and treat every victim coming to the clinic free of charge.

\section{Study Design}

A retrospective descriptive study was employed.

\section{Study Population}

Selected eligible numbers of survivors' charts in the last 3 years (from August 19, 2014 to February 15, 2018) period 
were the study population. Charts that were completed with the required variables were included in the study.

\section{Sample Size and Sampling Technique}

A sample of 178 charts were selected and reviewed for the descriptive study. All the charts available within the specified period $(\mathrm{N}=229)$ were located and framed in the sampling procedure using ordered chart numbers. A systematic random sampling technique was applied by calculating the $\mathrm{k}$ interval $(\mathrm{k}=2)$. After having the first card using lottery method, every 2 cards were selected until the final frame.

\section{Data Collection Method and Tool}

The Medical Records Unit was approached to identify charts/records of sexual assault within the study period and gathered data on those victims who had experienced any form of sexual assault and got their cases managed there. A sexual assault case was defined as any person, irrespective of age and sex, reporting any type of nonconsensual sexual activity. All the selected records of survivors were coded prior to abstraction and any discrepancies in coding were reviewed jointly and discussed for clarity. All the sampled charts/records were reviewed and information was extracted using a carefully developed structured checklist. Data were abstracted by four trained nurse professionals who were not working in JUMC and supervised by one senior gynecology and obstetric specialist on a daily basis.

\section{Method of Data Analysis}

The gathered data were checked for completeness, cleaned, and entered into EPI data 3.1, and exported to SPSS version 21.0 for statistical analyses. Quantitative data was summarized in frequencies and proportions. Proportions were mainly used to describe response to each variable. All appropriate data were presented using descriptive statistics in the form of narration and tables.

\section{Data Quality Management}

The structured checklist was pre-tested in Shenen Gibe Hospital 1 month ahead of the actual data collection on $10 \%$ (18) of records and was reviewed for appropriateness of wording and clarity of both contents and sequence of items in relation to patient chart order. Data collectors were trained before and after pretest on content, coding, review process, and data abstraction form. The completeness and consistency of the completed checklist were checked every other day.

\section{Ethical Consideration}

Ethical approval was obtained from the Institutional Review Board (IRB) of Health Institute, Jimma University with Ref. No: IHRPGD/3025/2018, dated: 7/ $2 / 2018$. A formal letter of request for cooperation was written to JUMC and respective offices including Sexual Violence Clinic. Confidentiality and anonymity were secured using codes. However, informed consent was not needed since secondary data were reviewed from earlier patients' charts and records retrospectively. This study was conducted in accordance with the Declaration of Helsinki.

\section{Results}

\section{Socio-Demographic Characteristics}

The age of sexual assault survivors ranged from 2-18 years with the mean age of $12( \pm 3)$ years. Most $(95.7 \%)$ of the victims were females. About half of the survivors $(51.3 \%)$ were from urban areas outside Jimma Town, and survivors from rural areas accounted for $16.6 \%$. Almost all $(99.5 \%)$ of the survivors were single, living with family and/or relatives, and married women accounted for only $0.5 \%$. More than three-quarters $(79.1 \%)$ of the survivors were students (See Table 1).

\section{Circumstances of Survivors}

Nearly half $(47.1 \%)$ of the assailants were known to the survivors, while the majority $(80.7 \%)$ of the assaults were committed at home. More than three-quarters $(83.3 \%)$ of the survivors were assaulted once, while $8.8 \%$ were assaulted four or more times. In $72 \%$ of cases, the police station was the first institution to which the crime of sexual assault was reported, followed by health institution, which accounts for $14.4 \%$. Sixty-nine percent were taken to the hospital by police, while $17.1 \%$ were taken by their family. In terms of time, $68.4 \%$ of all victims were assaulted at night time, while $31.6 \%$ were assaulted during day time. Methods of coercing the victims include verbal threats (47.1\%), physical force (44.4\%), knife (3.2\%), and gun (2.1\%) (See Table 2).

\section{Reporting Time and Related Injury of Survivors}

The time interval between the incident of sexual assault (rape) and disclosure (reporting) varied mainly from 24 hours to 6 or more days. In only $2.7 \%$ of sexual assault cases were reports made within 24 hours, while $50 \%$ of the cases were reported within 6 or more days after the incident. 
Table I Socio-Demographic Characteristics of Survivors of Sexual Assault Managed in JUMC, February 15, 2018 to April 15, 2018, Jimma Town, Southwest Ethiopia

\begin{tabular}{|l|l|}
\hline Variable & Number (\%) \\
\hline Age in years & \\
I-4 years & $9(4.8)$ \\
5-9 years & $25(13.4)$ \\
I0-14 years & $76(40.6)$ \\
$>$ I4 years & $77(41.2)$ \\
\hline Address & \\
Urban (jimma) & \\
Urban (nearby town) & $60(32.1)$ \\
Rural & $96(51.3)$ \\
\hline Sex & $31(16.6)$ \\
\hline Male & \\
Female & $8(4.3)$ \\
\hline Occupation & $179(95.7)$ \\
\hline Student & \\
Maid & Housewife \\
Other & $148(79.1)$ \\
\hline Current survivors' relationship status & $29(15.5)$ \\
Single & $1(0.5)$ \\
Married & $9(4.8)$ \\
\hline Educational status & \\
Illiterate & $86(99.5)$ \\
Literate & $1(0.5)$ \\
\hline
\end{tabular}

With respect to the lesion associated with sexual assault, $51.9 \%$ had perennial lacerations, 7.5\% hymeneal tears without bleeding, and 7\% hymeneal tears with bleeding. Among those with hymeneal tears, $13 \%$ had associated nongenital lesions, of these $4.8 \%$ had sustained abrasions. Fortunately, $28 \%$ of the survivors had no genital injuries. Perennial laceration was a type of injury most commonly reported by pre-adolescents, who are under 10 years old, when sexual assault was committed among those age groups (See Table 3).

\section{Laboratory Investigation Performed for Sexual Assault Survivors}

Out of the studied sexual assault victims, 75.9\%, 58.3\%, $54.5 \%$, and $96.8 \%$ underwent pregnancy test, VDRL,
Table 2 Circumstances of Survivors of Sexual Assault Managed in JUMC, February 15, 2018 to April 15, 2018, Jimma Town, Southwest Ethiopia

\begin{tabular}{|c|c|}
\hline Variables & Number (\%) \\
\hline \multicolumn{2}{|l|}{ Type of sexual assault } \\
\hline Committed & $126(67.4)$ \\
\hline Attempted & $61(32.6)$ \\
\hline \multicolumn{2}{|l|}{ Route of assault } \\
\hline Vaginal & $119(94.4)$ \\
\hline Anal & $5(4.0)$ \\
\hline Oral & $2(1.6)$ \\
\hline \multicolumn{2}{|l|}{ Brought to hospital by } \\
\hline Her/His own & $4(2.1)$ \\
\hline Family/Relative & $47(25.1)$ \\
\hline Police & $129(69.0)$ \\
\hline Guardian & I (0.5) \\
\hline Other & $6(3.2)$ \\
\hline \multicolumn{2}{|l|}{ Alcohol use by assailant } \\
\hline Yes & $6(3.2)$ \\
\hline No & $3(1.6)$ \\
\hline Unknown & $178(95.2)$ \\
\hline \multicolumn{2}{|l|}{ Time of assault } \\
\hline Day & $59(31.6)$ \\
\hline Night & $128(68.4)$ \\
\hline \multicolumn{2}{|l|}{ Number of times assaulted } \\
\hline I time & $105(83.3)$ \\
\hline $2-3$ times & $10(8.0)$ \\
\hline$\geq 4$ times & II (8.8) \\
\hline \multicolumn{2}{|l|}{ Perpetrators relationship } \\
\hline Stranger & $27(14.4)$ \\
\hline Acquaintance & I5I (80.7) \\
\hline Relative & I (0.5) \\
\hline Family member & $8(4.3)$ \\
\hline \multicolumn{2}{|l|}{ Place of assault/Violence } \\
\hline Own/Victims home & 39 (20.9) \\
\hline Assaults/perpetrator's home & $88(47.1)$ \\
\hline School & $33(17.6)$ \\
\hline Garden/park & $6(3.2)$ \\
\hline Bush/Forest & I6 (8.6) \\
\hline Others & $5(2.7)$ \\
\hline \multicolumn{2}{|l|}{ First institution } \\
\hline Health institution & $27(14.4)$ \\
\hline Police station & $136(72.7)$ \\
\hline Kebele/Village administration & $19(10.2)$ \\
\hline Other & $5(2.7)$ \\
\hline
\end{tabular}

(Continued) 
Table 2 (Continued).

\begin{tabular}{|l|l|}
\hline Variables & Number (\%) \\
\hline Mechanism of force & \\
Verbal threats & $88(47.1)$ \\
Physical force & $83(44.4)$ \\
Knife & $6(3.2)$ \\
Gun & $4(2.1)$ \\
Other & $6(3.2)$ \\
\hline
\end{tabular}

Table 3 First Time Presentation of Survivors of Sexual Assault and Related Injuries Managed in JUMC, February 15, 2018 to April 15, 2018, Jimma Town, Southwest Ethiopia

\begin{tabular}{|l|l|}
\hline Variables & $\begin{array}{l}\text { Number } \\
\text { (\%) }\end{array}$ \\
\hline $\begin{array}{l}\text { Time of presentation to the Hospital after assault } \\
\text { I day }\end{array}$ & $5(2.7)$ \\
$2-3$ days & $34(18.2)$ \\
$4-5$ days & $47(25.1)$ \\
$\geq 6$ days & $101(50.0)$ \\
\hline Genital injuries & \\
Hymeneal tear with bleeding & $13(7.0)$ \\
Hymeneal tear without bleeding & $14(7.5)$ \\
Perennial tear without bleeding & $1(0.5)$ \\
Perennial laceration & $97(51.9)$ \\
None & $54(28.9)$ \\
Other & $8(4.3)$ \\
\hline Non-genital (any body part including neck and head) & \\
injuries & \\
Abrasion & $9(4.8)$ \\
Bruise & $6(3.2)$ \\
Ecchymosis & $5(2.7)$ \\
Laceration & $5(2.7)$ \\
None & $160(85.6)$ \\
Other & $2(1.1)$ \\
\hline
\end{tabular}

HBsAg, and HIV test, respectively. The test results were positive at the time of evaluation for pregnancy for $3.2 \%$ and $1 \%$ for VDRL test. Vaginal swab for sperm analysis was not done at all and $98.9 \%$ of the survivors received the medico-legal certificate (see Table 4).

\section{Interventions Offered to Survivors}

Regarding the therapeutic interventions for potentially eligible survivors, a large majority $(86.6 \%)$ of the victims did not receive the STI prophylaxis; all of the survivors did not receive hepatitis B prophylaxes, and $91.4 \%$ of them were not given post-exposure prophylaxis. Emergency
Table 4 Laboratory Investigation Performed and Medico Legal Issues of Sexual Assaults Managed in JUMC, February 15, 2018 to April 15, 2018, Jimma Town, Southwest Ethiopia

\begin{tabular}{|c|c|}
\hline Variables & $\begin{array}{l}\text { Number } \\
\text { (\%) }\end{array}$ \\
\hline \multicolumn{2}{|l|}{ Pregnancy test } \\
\hline Positive & $6(3.2)$ \\
\hline Negative & $136(72.7)$ \\
\hline Not done & $45(24.1)$ \\
\hline \multicolumn{2}{|l|}{ Screening done for VDRL/RPR } \\
\hline Positive & $\mathrm{I}(0.5)$ \\
\hline Negative & $108(57.8)$ \\
\hline Not done & $78(4 \mid .7)$ \\
\hline \multicolumn{2}{|l|}{ Gram stain } \\
\hline Not done & $187(100)$ \\
\hline \multicolumn{2}{|l|}{$\mathrm{HBS}$ Ag } \\
\hline Negative & $102(54.5)$ \\
\hline Not done & $85(45.5)$ \\
\hline \multicolumn{2}{|l|}{ HIV test conducted } \\
\hline Negative & $181(96.8)$ \\
\hline Not done & $6(3.2)$ \\
\hline \multicolumn{2}{|l|}{ Vaginal swab for sperm analysis } \\
\hline Not done & $187(100)$ \\
\hline \multicolumn{2}{|l|}{$\begin{array}{l}\text { Medico-legal certificate given (containing diagnostic } \\
\text { result, victim's status and legal document to be } \\
\text { presented at court) }\end{array}$} \\
\hline Yes & $185(98.9)$ \\
\hline No & $2(1.1)$ \\
\hline
\end{tabular}

contraception was given only to $8 \%$ of the survivors. A large majority (84.5\%) of the victims obtained counseling and psychosocial support during their visit to the clinic (See Table 5).

\section{Discussion}

This is a three-year retrospective study of cases of sexual assaults whose records were found at JUMC. Although there could be some gaps in the accuracy of information on sexual assaults from institution-based study, it is the only way by which individual victims are identified and assessed. In this study, $81.8 \%$ of the sexual assaults were committed on children aged $10-18$ years. Most (95.7\%) of the survivors were females, and still there were some male victims, though homosexuality is forbidden by law in Ethiopia. School girls formed a high proportion of victims due to unknown reasons in this study, while there were a number of rules and regulations in place. This finding is 
Table 5 Provision of Interventions and Follow-Up Status by the Time of Presentation to Medical Center of Survivors of Sexual Assaults Managed in JUMC, February 15, 2018 to April 15, 2018, Jimma Town, Southwest Ethiopia

\begin{tabular}{|l|l|}
\hline Variables & Number (\%) \\
\hline $\begin{array}{l}\text { Provision of STIs prophylaxis } \\
\text { Yes }\end{array}$ & $25(13.4)$ \\
No & $162(86.6)$ \\
\hline $\begin{array}{l}\text { Provision of Hepatitis B prophylaxis } \\
\text { No }\end{array}$ & $187(100)$ \\
\hline $\begin{array}{l}\text { Provision of post-exposure prophylaxis } \\
\text { Nes }\end{array}$ & $16(8.6)$ \\
\hline $\begin{array}{l}\text { Provision of emergency contraception } \\
\text { Yes }\end{array}$ & $171(91.4)$ \\
\hline No & $15(8.0)$ \\
\hline $\begin{array}{l}\text { Did the victim have wound? } \\
\text { Yes }\end{array}$ & $172(92.0)$ \\
\hline No & $1(0.5)$ \\
\hline Receive counseling and psycho-social support & $186(99.5)$ \\
Yes & $158(84.5)$ \\
No & $29(15.5)$ \\
\hline $\begin{array}{l}\text { Other services provided to the victim } \\
\text { NT vaccination } \\
\text { Medical/surgical treatment }\end{array}$ & $1(0.5)$ \\
\hline Revisit the hospital for follow-up & $10.5)$ \\
\hline
\end{tabular}

almost in line with the studies conducted in Ethiopia and other African countries. ${ }^{15,17-23}$ Children are less likely to give resistance to their assailants due to physical incompetency and traditional harmful practices that empower males and older people, living in societies which do not have adequate institutional and programmatic protections against child sexual assault coupled with cultural norms that promote or glorify violence, ultimately increasing child sexual assaults. ${ }^{6}$ In $85.6 \%$ of the cases, the victims knew their assailants. This is a worldwide common scenario where sexual assault by a stranger is usually uncommon; rather, sexual assault starts at home, perpetrated by someone in the neighborhood, or in the surrounding environment with some degree of acquaintance. Hence, our finding is consistent with what was reported in different studies. ${ }^{7,20,21,23-26}$ We found it very strange that there were no victims older than 18 years. We expected an older women violence report but it was absent in the reviewed charts. The medical center (assault clinic) is freely accessible for any age group who want to get care. In the context, older women's violence was mostly not reported (under reported) due to fear of stigma and discrimination. If they reported and people around them hear that, they may not get married in the future, since men do not want to marry previously assaulted women. This may be one of the reasons for not reporting. However, we cannot make conclusions on its complete absence since there are nonreviewed charts.

Assailants in $80.7 \%$ of cases had some sort of acquaintance, which explains why the majority of sexual assaults occurred in the neighborhood and assaults/perpetrators' home where the course of action had a high possibility of being hidden and kept unreported or reported in an obscured manner. Despite the popular belief that most children are sexually, psychologically, and physically victimized by strangers in unknown places, the findings of the study further implicate that sexual abuse could happen to any child, irrespective of the degree of attachment between perpetrators and victims and at any place including the victims home and at any time.

The time interval between the inflicted sexual assault and divulgence of the action varied widely from 24 hours to 6 or more days. About a quarter $(25.1 \%)$ of victims were reported within 4-5 days, while 50\% reported within 6 or more days. The wide variation in the interval of disclosure or reporting could be imputed to threats of violence including death threat. ${ }^{22}$ Threat from the assailant is the most common means of subduing the victims. It is well known that children explicitly believe assailants threats and family would not believe so they prefer not to report until parents discovered the sexual assault by themselves. ${ }^{27}$

More than two-thirds (72.2\%) of the victims had reported to the police prior to presentation to the medical center. This may figure that victims did not realize about the serious health consequences of sexual assault due to delay in seeking medical care but more interested in having their assailants punished. It is crystal clear that an official report to the police will mandate a medical center assessment and report which ensures the appropriate medico-legal certificate. ${ }^{15,27}$ Hardly any number of victims had body bruise (3.2\%) and body abrasion (4.8\%), which may be due to the late presentation which allowed for the healing or submission of the victim and may be achieved by emotional manipulation or verbal threats, contributing to avoidance of physical injuries. 
It is known that the standard of clinical management of sexual violence involves the three basic elements of health response, clinical care/treatment of injury, collecting evidence or documentation to support a criminal investigation as appropriate to the context and referral as required. ${ }^{28}$ The treatment package includes getting forensic materials, detecting prior pregnancy screening for sexually transmitted infections including HIV and provision of adequate contraception, post exposure prophylaxis, supportive psychological counseling and provision of medico legal certificate. ${ }^{29}$ However, these vital services were not actually offered to the needy victims. It is the role of those working against violence to provide support to the health actors in sensitizing medical and non-medical personnel to the diverse needs of survivors and promoting compassionate care. Accordingly, different actors should also facilitate coordination with health and other sectors. ${ }^{28}$

While the aforementioned case is the reality of managing sexual assaults in some places, our study finding revealed that $24 \%$ of sexual survivors were not checked for pregnancy test, $41.7 \%$ of the victims did not get the test for VDRL, and $45.5 \%$ for HBs Ag. Almost all victims were given HIV test, but none of them was considered for prophylaxis. There is a wide variation between the study conducted in Ethiopia and other African regions with our current finding on medical care provided to survivors, where the majority of the studies tell us all care packages were availed to survivors as per the guideline and protocol in their setting. In the case of our study setting, survivors were not lucky to get all the standard care packages required. This may be justified by the nature of the assault, service readiness and preparedness, disclosure time which contributed to a low proportion of service provision. At the same time, this implies that there is a low-level attention given to the problem of sexual assault. In addition, $92 \%$ of the survivors were not offered emergency contraception; this is higher as compared to the study conducted in Ethiopia, ${ }^{15,30}$ and Zambia, ${ }^{31}$ but similar with the study conducted in Nigeria. ${ }^{22}$

In our study, no forensic samples were collected, no sperm analysis was done, and there was no referral to higher level and/or psychiatry clinic. This finding is consistent with the studies conducted in Ethiopia and Nigeria. ${ }^{22,32}$ While individual characteristics may increase the risk and result in serious damage, intervention services need better attention for most victims since they need to get enough investigation and treatment to tackle the consequences that will probably occur after the violence.
There is no doubt, for instance, providing emergency contraception will help the survivors not to face further pregnancy challenges and psychological trauma ahead. Accordingly, we also recommend that regular in-service training of healthcare providers and utilization of written protocol and guideline for the management of sexually assaulted victims should be provided to promote postrape care. In addition, availability of protocol/guideline and all the needed equipment should be ensured from the administration wing to ease the provision of care in the full package so as to reduce the physical and psychosocial complications of sexual assault and thereby ensure recovery of their health and wellbeing.

Sexual assault is a widespread dreadful wrongdoing and under-reported, with deleterious psychological, social, and physical out-turn in its sufferer. Most of the victims face violence during the day time. The majority of the survivors gave priority to reporting to police over seeking healthcare early, which caused a delay in healthcare provision. A small number of sexual assaults were reported to the health institution within 24 hours of the incident; the longer the interval the lower the quality of evidence, and the higher the risk of negative health outcomes, and this is an alarming kind of finding. Therefore, there is a need for more comprehensive, integrated, and timely investigation and care for victims of sexual assault in order to prevent serious damage and deter assailants as well. This may be realized by continuous monitoring and evaluation of protocol utilization by all concerned bodies from household and community up to institutional level. Sexual assault prevention and response are closely interlinked. For this reason, better institutional responses to sexual violence may contribute to long-term prevention at community and societal levels. Lack of coordination among sectors can be a barrier both for prevention and comprehensive service responses.

In conclusion, limited and inadequately documented official records of victims may not provide a comprehensive picture of the problem in a particular setting. However, we acknowledge that the existing documents, which are relevant in some aspects specific to the study variables, contribute to implications for prevention, treatment, follow-up, as well as design of new procedures to ensure better control of such crimes in the study area and Ethiopia as a whole. In this regard, sexual assaults' profile was reviewed and described well. However, we recommend studies focusing on driving factors of child violence from social, cultural, and technological views as well as treatment packages after victim's arrival at health institutions and associated factors should 
be investigated using a strong design. Although the study has been constrained by a small sample size, it has attempted to address the topic of national and global concerns by analyzing the victims' circumstances, service gaps, and several other crucial factors generating relevant evidence to promote prospective studies.

\section{Disclosure}

The authors have disclosed that they do not have any potential conflicts of interest for this work, financial or otherwise.

\section{References}

1. Walby S, Towers J, Francis B, et al. Overview of the world's best practices for rape prevention \& for assisting women victim of rape; 2013. Available from: http://www.europarl.europa.eu/studies. Accessed March 4, 2021.

2. Estelle B. Freedman, Redefining Rape. Sexual Violence in the Era of Suffrage and Segregation. Cambridge and London England: Harvard University Press; 2013.

3. United Nations. Keeping the promise ending violence against children by 2030. New York July, 2019. 2019. Sales no:E.19.1.13. ISBN:978-92-1- 101413-6.

4. Kristen S, Jeannie N, Debra G. Child Protection in Families Experiencing Domestic Violence. 2nd ed ed. Administration for Children and Families, Administration on Children, Youth, and Families, Children's Bureau, Office on Child Abuse and Neglect; 2018.

5. Hillis S, Mercy J, Amobi A, et al. Global prevalence of past-year violence against children: a systematic review and minimum estimates. Pediatrics. 2016;137(3):20154079. doi:10.1542/ peds.2015-4079

6. WHO. WHO Guide Line for the Health Sector Response to Child Maltreatment. WHO; 2019.

7. ABaAP. Preventing Child Maltreatment: A Guide to Taking Action and Generating Evidence. WHO Library Cataloging-in-Publication Data; 2006.

8. World Health Organization. Global plan of action to strengthen the role of the health system within a national multisectoral response to address interpersonal violence, in particular against women and girls, and against children; 2016. Available from: https://www.who.int/ reproductivehealth/publications/violence/global-plan-of-action/en/ Accessed March 4, 2021.

9. United Nations, Office of the Special Representative of the SecretaryGeneral on Violence against Children. Violence against children; toward aworld free from violence. Global survey on violence against children. Office of the SRSG; 2013.

10. USAID. GBV definition prevalence and global statistics,toolkit for integrating GBV prevention and response into economic growth; 2012. Available from: https://www.usaid.gov/sites/default/files/docu ments/1865/USAID\%20Toolkit\%20GBV\%20EG\%20Final\% 20Section\%202.pdf.Accessed March 4, 2021.

11. Jewkes R, Abrahams N. The epidemiology of rape and sexual coercion in South Africa: an overview. Soc Sci Med. 2002;55 (7):1231-1244. doi:10.1016/s0277-9536(01)00242-8.

12. Ajuwon A, Olley BO, Akin-Jimoh I, Akintola O, Akin-Jimoh E. Experience of sexual coercion among adolescents in Ibadan, Nigeria. Afr J Reprod Health. 2001;5(3):120-131. doi:10.2307/ 3583330
13. Kullima AA, Kawuwa MB, Audu BM, Mairiga AG, Bukar M. Sexual assault against female Nigerian students. Afr $J$ Reprod Health. 2010;14.

14. Worku A, Addisie M. Sexual violence among female High school students in Debark North West Ethiopia. East African J. 2002;79.

15. Amenu D, Hiko D. Sexual assault: pattern and related complications among cases managed in Jimma University Specialized Hospital. Ethiopian J Health Sci. 2014;24(1):3-14. doi:10.4314/ejhs.v24i1.1

16. WHO. INSPIRE handbook: action for implementing the seven strategies for ending violence against children, 2018. IGO; 2018. Available from: http://apps.who.int/iris. Accessed March 4, 2021.

17. Mulatie M. Physical and psychological child abuse in Ethiopia: implications for intervention. J Psychol Psychother. 2014;04(02). doi:10.4172/2161-0487.1000137

18. Lakew Z. Alleged cases of sexual assault reported to two Addis Ababa Hospital. East African J. 2001;78.

19. Meel BL. Incidence of HIV infection at the time of incident reporting, in victims of sexual assault, between 2000 and 2004, in Transkei, Eastern Cape, South Africa. Afr Health Sci. 2005;5.

20. Adeleke NA, Hassan MB, Asekun-Olarinmoye EO, Olowookere AS, Komolafe JO. Sexual assault against women at Osogbo southwestern Nigeria. Niger J Clin Pract. 2012;15(2):190-193. doi:10.4103/11193077.97316

21. Daru PH, Osagie EO, Pam IC, Mutihir JT, Silas OA, Ekwempu CC. Analysis of cases of rape as seen at the Jos University Teaching Hospital, Jos, North Central Nigeria. Niger J Clin Pract. 2011;14 (1):47-51. doi:10.4103/1119-3077.79240

22. Akinlusi FM, Rabiu KA, Olawepo TA, Adewunmi AA, Ottun TA, Akinola OI. Sexual assault in Lagos Nigeria: a five year retrospective review. BMC Women Health. 2014;14.

23. Akhiwu W, Umanah IN, Olueddo AN. Sexual assaults in Benin City, Nigeria. TAF Prev Med Bull. 2013;12(4):377-382. doi:10.5455/ pmb.1-1303366742

24. Iliyasu Z, Abubakar IS, Aliyu MH, Galadanci HS, Salihu HM. Prevalence and correlates of gender-based violence among female university students in Northern Nigeria. Afr J Reprod Health. 2011;15(3):111-119.

25. Ononge S, Wandabwa J, Kiondo P, Busingye R. Clinical presentation and management of alleged sexually assaulted females at Mulago hospital, Kampala, Uganda. Afr Health Sci. 2005;5.

26. Mugawe D, Powell A. Born to High Risk: Violence Against Girls in Africa: Report Prepared for the Second International Policy Conference on the African Child. African Child Policy Forum; 2006.

27. Lessing J. Primary care provider interventions for the delayed disclosure of adolescent sexual assault. J Pediatric Health Care. 2005;19(1):17-24. doi:10.1016/S0891-5245(04)00181-6

28. WHO-UNHCR. Clinical Management of Rape Survivors Developing Protocols for Use with Refugees and Internally Displaced Persons Revised Edition. WHO Library Publication Data; 2004.

29. WHO. Guidelines for Medico-Legal Care for Victims of Sexual Violence. WHO Library Cataloguing-in-Publication Data; 2003.

30. Worku F, Abdella A. Emergency contraception provision for sexually assaulted women at health facilities in Addis Ababa, Ethiopia. Ethiopian J Reprod Health. 2009;3.

31. Kilonzo N, Theobald SJ, Nyamato E, et al. Emergency contraception and care for sexual assault. Emerg Contracept afrique bull. 2004;2/2.

32. Martin SL, Young SK, Billings DL, Bross CC. Health care-based interventions for women who have experienced sexual violence: a review of the literature. Trauma Violence Abuse. 2007;8(1):3-18. doi: $10.1177 / 1524838006296746$ 


\section{Publish your work in this journal}

Adolescent Health, Medicine and Therapeutics is an international, peer-reviewed, open access journal focusing on health, pathology, and treatment issues specific to the adolescent age group. All aspects of health maintenance, preventative measures and disease treatmen interventions are addressed within the journal and practitioners from all disciplines are invited to submit their work as well as healthcare researchers and patient support groups. The manuscript management system is completely online and includes a very quick and fair peerreview system. Visit http://www.dovepress.com/testimonials.php to read real quotes from published authors. 